\title{
Communication \\ The Impact of Salts on the Ice Recrystallization Inhibition Activity of Antifreeze (Glyco)Proteins
}

\author{
Romà Surís-Valls and Ilja K. Voets * \\ Laboratory of Self-Organizing Soft Matter, Laboratory of Macro-Organic Chemistry, Department of Chemical \\ Engineering and Chemistry \& Institute for Complex Molecular Systems, Eindhoven University of Technology, \\ Post Office Box 513, 5600 MD Eindhoven, The Netherlands \\ * Correspondence: i.voets@tue.nl; Tel.: +31-40-247-5303
}

Received: 10 July 2019; Accepted: 31 July 2019; Published: 6 August 2019

\begin{abstract}
Antifreeze (glyco)proteins ( $\mathrm{AF}(\mathrm{G}) \mathrm{Ps}$ ) have received increasing attention as potential cryopreservation agents since their discovery in the 1970s. While cryopreservation strategies for specific cells (such as red blood cells) are successful and widely implemented, preservation of other cell types, tissues and whole organs remains challenging. This is due to the multifactorial nature of the freeze-thaw damage, the complexity of preserving biological matter and the (country-to-country) variability of the employed procedures and regulations. $A F(G) P s$ are well-known for their ability to modulate ice crystal growth morphology and ice recrystallization inhibition (IRI), both of which are considered key contributors to freeze-thaw damage. To date, however, the impact of $\mathrm{AF}(\mathrm{G}) \mathrm{Ps}$ on cell survival remains at best partially understood as conflicting results on the benefits or disadvantages of including $\mathrm{AF}(\mathrm{G}) \mathrm{P}$ in cryopreservation strategies remain unelucidated. We hypothesize that variability in the additives in the cryopreservation media contributes to the observed discrepancies. To critically examine this idea, we monitored the inhibition of ice recrystallization by $A F(G) P$ in the presence of various salts using a quantitative analysis of optical microscopy images via the Lifshitz-Slyozov-Wagner (LSW) theory for Oswald ripening. We found that the addition of salts, which are used in culture and cryopreservation media, enhances the IRI activity of $A F(G) P s$, and that the magnitude of the enhancement was in line with the Hofmeister series. The size of ice crystals grown in $\mathrm{AFGP}_{1-5}$ and type III AFP samples containing chloride, phosphate and citrate ions were statistically smaller after $90 \mathrm{~min}$ of incubation than crystals grown in the absence of these salts. The ice recrystallization rates $\left(k_{\mathrm{d}}\right)$ of $\mathrm{AFGP}_{1-5}$ and type III AFP samples prepared at a fixed overall ionic strength of $100 \mathrm{mM}$ progressively decreased following the Hofmeister series for anions. Our results demonstrate that the performance of $A F(G) P s$ is significantly influenced by additives present in common cryopreservation media. It is thus important to conduct excipient compatibility experiments to identify potential incompatibilities between additives and $\mathrm{AF}(\mathrm{G}) \mathrm{Ps}$ in cryopreservation formulations.
\end{abstract}

Keywords: antifreeze proteins; ice recrystallization inhibition; hofmeister series

\section{Introduction}

While cryopreservation strategies for specific cells (such as red blood cells) are successful and widely implemented, preservation of other cell types, tissues and whole organs remains challenging. This is due to the multifactorial nature of freeze-thaw damage, the complexity of preserving biological matter and the (country-to-country) variability of the employed procedures and regulations. In many cases, cellular damage to cryopreserved cells, tissues and organs is induced by ice recrystallization during thawing [1,2]. Small molecules such as sugars, salts, alcohols and other small molecules are often used to mitigate these effects in a colligative fashion $[2,3]$. The disadvantage of this approach is the high 
concentration required to elicit a significant effect. Interestingly, antifreeze (glyco)proteins $(\mathrm{AF}(\mathrm{G}) \mathrm{Ps})$ inhibit ice recrystallization at far lower concentrations, as they act in a non-colligative manner $[4,5]$. $\mathrm{AF}(\mathrm{G}) \mathrm{Ps}$ have thus received widespread attention as potential cryopreservation agents [6], yet with limited success in practice. Some studies have shown how exposure to $A F(G) P s$ results in loss of cell survival after freeze-thawing steps in cryopreservation protocols, but others have reported greater cell survival after using the same proteins at comparable concentrations [7-10]. We hypothesize that such discrepancies in literature are related to different additives in the cryopreservation media.

At the end of the 19th century, Franz Hofmeister observed and quantified egg white protein precipitation triggered by the addition of different salts containing the same cation. Hofmeister's original work pointed towards ion specificity in the precipitation of proteins, where anions had a more pronounced effect than cations [11]. Direct ion-macromolecule interactions are likely responsible for most aspects of this singularity. Since Hofmeister's seminal work, ion-specific effects in line with the so-called Hofmeister series have been observed throughout biology in enzyme activities, protein stability and protein-protein interactions among others [12-14]. Interestingly, the thermal hysteresis (TH) activity exhibited by $\mathrm{AF}(\mathrm{G}) \mathrm{Ps}$ - quantified as the magnitude of the gap between the melting and freezing temperatures of an $\mathrm{AF}(\mathrm{G}) \mathrm{P}$ solution-was found to increase in the presence of various salts in accordance with the Hofmeister series [15-18]. Kristiansen and collaborators suggested that this is due to enhanced ice adsorption driven by a salt-induced reduction in AFP solubility in the solution surrounding the ice crystal [17]. While this TH enhancement by salts is well documented, their role in ice recrystallization inhibition (IRI) activity remains unresolved [19]. It is likely that salts also significantly alter IRI, as both IRI and TH activity originate from the ability of AF(G)P's to adhere to ice [5]. In this report we study the effect of salts from the Hofmeister series on the IRI activity of AF(G)Ps using the so-called 'sucrose sandwich assay' of IRI activity, which maintains a constant and low-ice volume fraction and allows the quantification of ice growth rate constants $\left(k_{\mathrm{d}}\right)$ [20-22]. We found that salts common in cryopreservation media enhanced the IRI activity of $A F(G) P s$ and that the magnitude of the enhancement was in line with the Hofmeister series. These findings suggest that systematic experiments of the compatibility between excipients and $\mathrm{AF}(\mathrm{G}) \mathrm{Ps}$ in cryopreservation formulations may shed further light on observed variabilities in the performance of $\mathrm{AF}(\mathrm{G}) \mathrm{Ps}$ as cryoprotectants.

\section{Materials and Methods}

\subsection{Materials}

Salt stock solutions of $1 \mathrm{M}$ were prepared by dissolving the desired amount of salt in ultrapure water. Sodium nitrate $\left(\mathrm{NaNO}_{3}\right)>99 \%$, sodium phosphate $\left(\mathrm{NaHPO}_{4}\right)>89 \%$, sodium citrate $\left(\mathrm{Na}_{3} \mathrm{C}_{6} \mathrm{H}_{7} \cdot 2 \mathrm{H}_{2} \mathrm{O}\right)$, disodium tetraborate $\left(\mathrm{Na}_{2} \mathrm{~B}_{4} \mathrm{O}_{7} \cdot 10 \mathrm{H}_{2} \mathrm{O}\right)>99.5 \%$ and sodium chloride $(\mathrm{NaCl})>99 \%$ (Acros Organics) were purchased from Fischer Scientific. AFGP ${ }_{1-5}$ and recombinant type III AFP QAE HPLC12 samples were prepared by mixing the protein with the different salted buffers in the right amounts to reach fixed protein concentrations of $5 \mathrm{nM}\left(\mathrm{AFGP}_{1-5}\right)$ and $500 \mathrm{nM}$ (rQAE), which are the IRI activity inflection points in the absence of added salts according to literature [5].

\subsection{Ice Recrystallization Inhibition (IRI) Assay}

To test the effect of specific ion interactions on the IRI activity of $A F(G) P s$ that bind the primary prism plane, we selected the sucrose sandwich assay. Classical quantitative methods for studying IRI activity, such as the splat assay and the capillary method, are not sensitive enough to detect small differences in IRI. The liquid volume fraction is too low and the ice volume fraction too high to reliably avoid false positives (i.e., to avoid qualifying (macro) molecules without ice affinity as inhibitors of ice recrystallization). In a sucrose sandwich assay, the liquid volume fraction is increased by addition of the innocuous solute sucrose, allowing molecules without ice affinity to freely defuse. IRI experiments are performed at a fixed concentration of $5 \mathrm{nM}\left(\mathrm{AFGP}_{1-5}\right)$ and $500 \mathrm{nM}$ (rQAE). We prepared these by sandwiching $2 \mu \mathrm{L}$ of sample between two cover slides, which was rapidly frozen $\left(20^{\circ} \mathrm{C} / \mathrm{min}\right)$ to $-40^{\circ} \mathrm{C}$ 
in a Linkam LTS420 stage attached to a Nikon ECLIPSE Ci-Pol Optical Microscope (Figures S1 and S2). The samples were then annealed at $-7^{\circ} \mathrm{C}$ for $90 \mathrm{~min}$, while microphotographs were taken every $2 \mathrm{~min}$ to follow the ice growth over time. All samples showed well-defined grain boundaries and frozen fractions lower than 0.3 , which made them suitable for the study of migratory recrystallization and minimized ice crystal accretion (Figure S3).

\subsection{Statistical Analysis}

The statistical analysis was performed in OriginPro 2015 (OriginLabs). Normal distributions of ice crystal radii were assessed by Shapiro-Wilk tests to properly analyze the statistical differences between data sets. The non-parametric Mann-Whitney-Wilcoxon test was used to identify statistical differences between the median values for the ice crystal radii at the end point of the experiment; $p$-values lower than 0.05 indicated statistical differences between compared sets.

\section{Results and Discussion}

Aiming to elucidate the effect of various salts commonly used in cryopreservation media, we compared the ice recrystallization inhibition (IRI) activity of antifreeze (glyco)proteins in the presence of sodium salts from the Hofmeister series for anions at a fixed overall ionic strength of $100 \mathrm{mM}$. We selected two widely studied fish antifreeze proteins, which varied three orders of magnitude in IRI activity in $30 \mathrm{wt} \%$ sucrose solutions. These are the globular fish type III antifreeze protein QAE HPLC12 (rQAE) from the ocean pout, and the glycosylated polypeptide AFGP $_{1-5}$ from Antarctic tooth fish. We analyzed the impact of sodium nitrate, sodium chloride, sodium borate, sodium phosphate and sodium citrate on their IRI activity by optical microscopy using the so-called sucrose sandwich assay, which allowed us to determine and monitor ice crystal grain size and ice growth rates over time.

First, a series of control experiments were performed to examine the impact of the added salts on the dimensions and growth rates of ice crystals in $30 \mathrm{wt} \%$ sucrose solutions without $\mathrm{AF}(\mathrm{G}) \mathrm{Ps}$. At the endpoint of the experiments, after an annealing time of $90 \mathrm{~min}$, Shapiro-Wilk tests identified log-normal distributions of ice crystal radii ranging in size between 0.8 and $14.4 \mu \mathrm{m}$ for all salted solutions without proteins (Figure 1a). The number average radius $<R>$ was smallest for sodium phosphate $(<R>=8.0 \mu \mathrm{m})$ and largest for sodium nitrate $(<R>=8.4 \mu \mathrm{m})$. Similarly, ice recrystallization rates $\left(k_{\mathrm{d}}=\partial<\mathrm{R}>3 / \partial \mathrm{t}\right)$ were smallest for sodium phosphate $\left(k_{\mathrm{d}}=7.1 \mu \mathrm{m}^{3} \mathrm{~min}^{-1}\right)$ and largest for sodium nitrate $\left(k_{\mathrm{d}}=7.9 \mu \mathrm{m}^{3} \mathrm{~min}^{-1}\right)$. All five anions increased the ice recrystallization rate by roughly $30 \%$, from $\sim 5.5 \mu \mathrm{m}^{3} \mathrm{~min}^{-1}$ for unsalted to $7.5 \pm 0.3 \mu \mathrm{m}^{3} \mathrm{~min}^{-1}$ for salted $30 \mathrm{wt} \%$ sucrose solutions (Figure $1 \mathrm{~b}$ ). As the addition of any solute to the control sucrose solution alters its freezing point and consequently changes its ice volume fraction [21], $\varphi$, we must rescale all ice crystal growth rates to an ice crystal volume fraction of zero, $\varphi^{0}$, for an appropriate comparison (Figure 1c). As expected, after elimination of this influence of differences in ice crystal volume fractions on $k_{d}$, we found that none of the anions had a statistically significant impact on the ice crystal growth rates (i.e., the added salts did not significantly modulate the diffusion of water molecules).
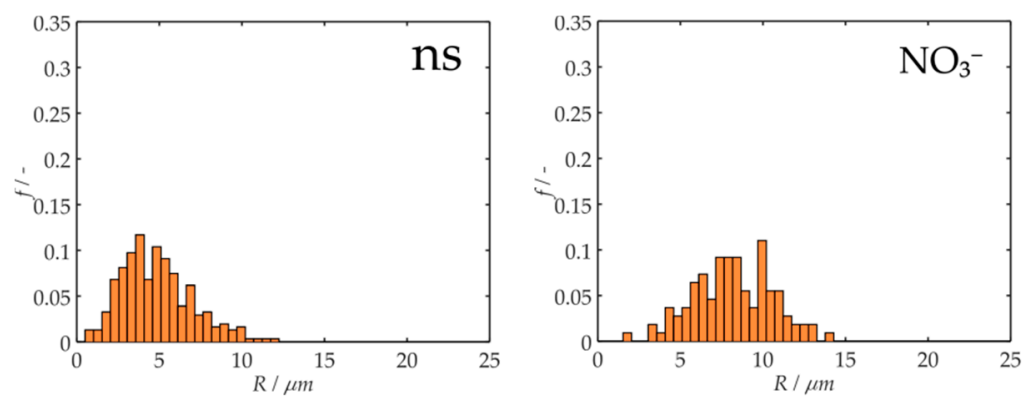

(a)

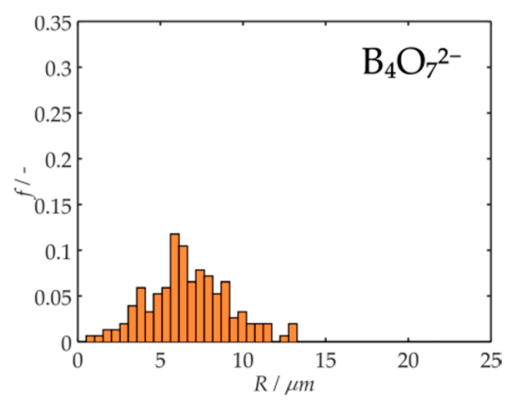

Figure 1. Cont. 


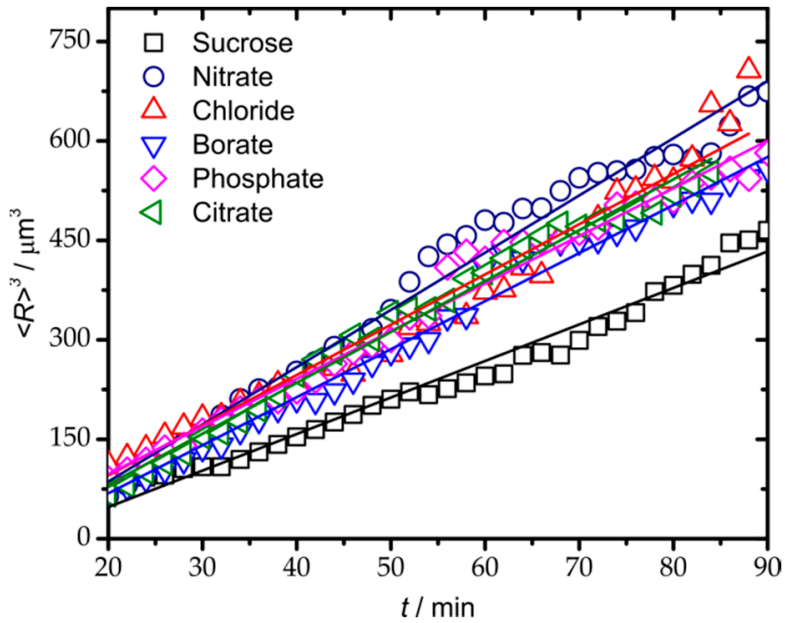

(b)

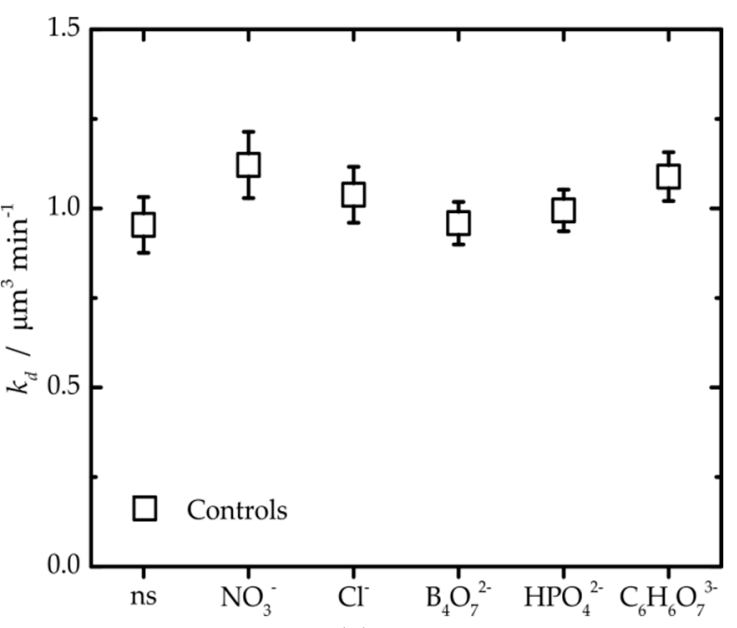

(c)

Figure 1. Analysis of the results obtained for reference solutions of the different salts studied. (a) Ice crystal radii distributions for a sample containing MilliQ water and $30 \mathrm{wt} \%$ sucrose (ns); $100 \mathrm{mM}$ total ionic strength of sodium nitrate and $30 \mathrm{wt} \%$ sucrose $\left(\mathrm{NO}_{3}{ }^{-}\right)$; and $100 \mathrm{mM}$ total ionic strength of disodium tetraborate and $30 \mathrm{wt} \%$ sucrose $\left(\mathrm{B}_{4} \mathrm{O}_{7}{ }^{2-}\right)$. (b) Samples containing $500 \mathrm{nM}$ rQAE in $30 \mathrm{wt} \%$ sucrose (black), sodium nitrate (navy blue), sodium chloride (red), sodium borate (blue), sodium phosphate (magenta) and sodium citrate (olive). (c) Ice growth rates for the salted reference solutions with a zero ice volume fraction regime.

Next, the impact of the salts on the IRI activity of AFGP $_{1-5}$ was examined (Figure 2). The ice crystal distributions in all $5 \mathrm{nM} \mathrm{AFGP}_{1-5}$ samples, both with and without added salts, were log-normal (Figures S4 and S5). Most distributions were also considerably skewed due to the presence of large amounts of small ice crystals. These remained for prolonged periods of time due to $\mathrm{AF}(\mathrm{G}) \mathrm{P}$ adsorption onto ice grains, which impeded both the melting of small ice crystals and the growth of large ice crystals $[20,21]$. Consequentially, the median was found below the average mean radius for these $\mathrm{AFGP}_{1-5}$ samples. As AFGPs are potent ice recrystallization inhibitors, $<R>$ for the ice crystals remained considerably smaller (between 1.4 and $6.3 \mu \mathrm{m}$ ) in the salted sucrose solutions with AFGP $_{1-5}$ (Figure 2a) for all salts except sodium borate $(<R>\sim 6.9 \mu \mathrm{m})$. In accordance with LSW theory, we observed a linear increase in $<R>^{3}$ as a function of time for all $5 \mathrm{nM} \mathrm{AFGP}{ }_{1-5}$ samples (Figure 3a). The sodium salts significantly impacted the potency of $\mathrm{AFGP}_{1-5}$ to inhibit ice recrystallization as $k_{\mathrm{d}}$ rescaled to $\varphi^{0}$ varied significantly amongst the salted sucrose solutions at a fixed AFGP ${ }_{1-5}$ concentration. Ranking $\mathrm{AFGP}_{1-5}$ on the order of ascending IRI potency from the least to the most active, we found $\mathrm{B}_{4} \mathrm{O}_{7}{ }^{2-}<\mathrm{NO}_{3}{ }^{-}<$ $\mathrm{Cl}^{-}<\mathrm{HPO}_{4}{ }^{2-}<\mathrm{C}_{6} \mathrm{H}_{6} \mathrm{O}_{7}{ }^{3-}$ (Figure 3c). This trend in IRI activity followed the Hofmeister series for anions with the exception of sodium borate $\left(k_{\mathrm{d}}=3.9 \mu \mathrm{m}^{3} \mathrm{~min}^{-1}\right)$. In fact, $\mathrm{AFGP}_{1-5}$ showed the same ice growth rate in the presence of sodium borate as without any salt in the solution. The complete loss of TH activity of AFGPs upon addition of borate ions is well-documented. It is caused by the cross-linking of AFGPs through esterification of the glycosylated threonine amino acids, which are crucial for both TH and IRI activity [23,24]. As borate can react with both AFGPs and sucrose, all borate samples were prepared by dissolution of the proteins in the borate solutions prior to the addition of sucrose. Remarkably, the addition of a six-fold molar excess of borate ions to AFGPs did not eliminate IRI activity completely. If the ability to inhibit ice recrystallization were completely suppressed, the $k_{\mathrm{d}}$ values for sodium borate containing $\mathrm{AFGP}_{1-5}$ samples should have been similar to those of the borate control solution $\left(\sim 7.2 \mu \mathrm{m}^{3} \mathrm{~min}^{-1}\right)$. We attribute this differential impact of borate on TH and IRI activity to a borate concentration-dependent decrease in the adsorption rate of AFGPs to ice. Indeed, an earlier study demonstrated that AFGPs exposed to $0.3 \mathrm{M}$ of borate still adsorbed to ice seeds, albeit with three times less affinity, while TH activity was completely lost [25]. As ice-binding must be very 
strong for TH activity and less so for IRI activity, AFGPs exposed to low borate concentrations may be TH-defective yet IRI-active.

To examine whether the IRI activity of non-glycosylated antifreezes also follows the Hofmeister series for anions, we performed the same assays on rQAE at a concentration of $500 \mathrm{nM}$. This concentration was well suited for our purpose, as it is slightly below the inhibitory concentration for non-salted rQAE in $30 \mathrm{wt} \%$ sucrose, and thus a protein concentration at which additives that impact the IRI activity of rQAE would impact $k_{\mathrm{d}}$. The ice crystal radii distributions of most salted rQAE samples (with the exception of sodium nitrate) skewed towards smaller ice crystal sizes than the reference rQAE sample without added salt (Figure $2 b$ ). The mean dimensions of ice crystals at the endpoint of the rQAE IRI assay at $500 \mathrm{nM}(1.1<R>11.4 \mu \mathrm{m})$ were comparable to those of the AFGP $1-5$ IRI assay at a 100-fold lower concentration $(0.7<R>10.7 \mu \mathrm{m})$. Ranking IRI activity for rQAE from weak to high based on $k_{\mathrm{d}}$ at $\varphi^{0}$, we found $\mathrm{NO}_{3}{ }^{-}<\mathrm{Cl}^{-}<\mathrm{B}_{4} \mathrm{O}_{7}{ }^{2-}<\mathrm{HPO}_{4}{ }^{2-}<\mathrm{C}_{6} \mathrm{H}_{6} \mathrm{O}_{7}{ }^{3-}$ (Figure 3c). Once again, this trend is in line with the Hofmeister series for anions (this time without exceptions). Apparently, the reduction in borate concentration due to complexation of borate with sucrose was small, as its impact on ice recrystallization by rQAE was significant.

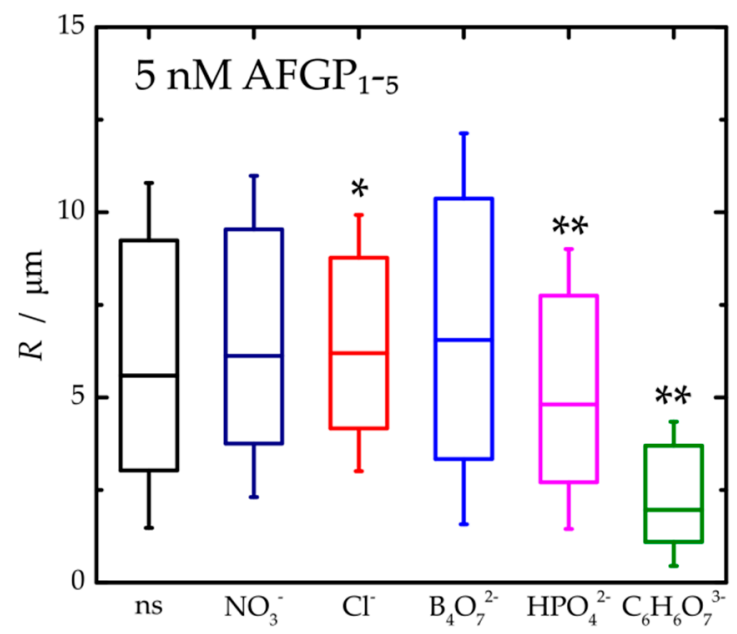

(a)

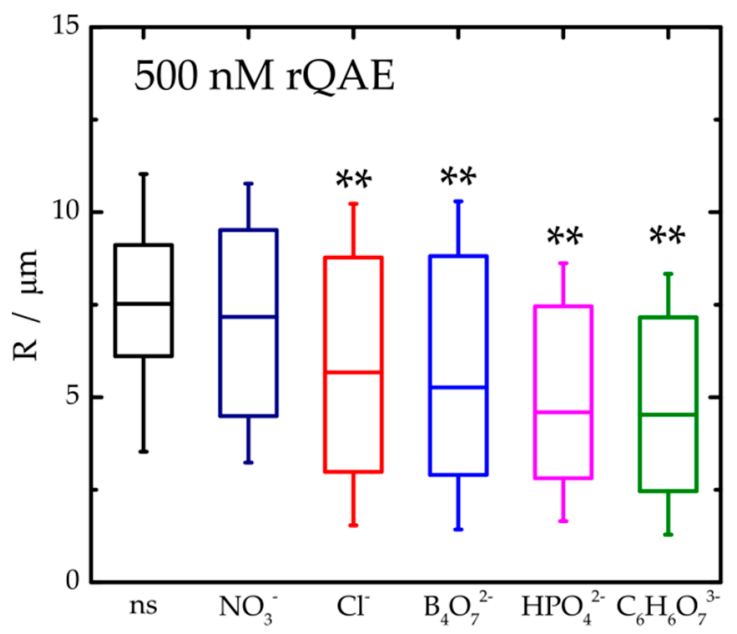

(b)

Figure 2. Boxplots of the ice crystal radii distributions after sample annealing at $-7^{\circ} \mathrm{C}$ for $90 \mathrm{~min}$. (a) Samples containing $5 \mathrm{nM} \mathrm{AFGP}{ }_{1-5}$ in $30 \mathrm{wt} \%$ sucrose (black), sodium nitrate (navy blue), sodium chloride (red), sodium borate (blue), sodium phosphate (magenta) and sodium citrate (olive). (b) Samples containing $500 \mathrm{nM}$ QAE in $30 \mathrm{wt} \%$ sucrose (black), sodium nitrate (navy blue), sodium chloride (red), sodium borate (blue), sodium phosphate (magenta) and sodium citrate (olive). Median (line), minimum and maximum radii observed (whiskers). ${ }^{*} p$-value $<0.05$, ${ }^{* *} p$-value $<0.01$.

Interestingly, our quantitative analysis of the ice crystal growth rates when rescaled to vanishingly small ice crystal volume fractions demonstrated that the IRI activity of both RQAE and AFGP $1-5$ could be significantly enhanced by the addition of $100 \mathrm{mM}$ sodium salts. Importantly, we arrived at the same conclusion and ranking of rQAE and $\mathrm{AFGP}_{1-5}$ in order of ascending potency if we used, as a quantitative metric of potency, the dimensionless parameter $r=\langle R\rangle_{90} /\langle R\rangle_{20}$, which corresponds to the ratio of the number average mean ice crystal radius at the endpoint of the IRI assay $\left\langle R>_{90}\right.$ to its equivalent at the start of the assay $<R>_{20}$ (Table S1). The salt-induced enhancement of IRI activity followed the Hofmeister series for anions for both proteins with the exception of sodium borate, as it reacted with the hydroxyl groups of the threonine-linked disaccharides on $\mathrm{AFGP}_{1-5}$, thus impairing the ice-binding properties of the protein. Differences in salt composition (both type and concentration) of cryopreservation media can thus significantly impact the inhibition of ice recrystallization by $A F(G) P s$, and may (partially) explain the apparently conflicting results in the scientific literature on the moderate success of $\mathrm{AF}(\mathrm{G}) \mathrm{Ps}$ as cryoprotectants. We attribute these salt effects to the same 
mechanisms put forward to rationalize the 'salting-out' of proteins, namely a salt-induced reduction in solubility due to specific interactions between salt ions and surface-accessible residues. For the antifreeze (glyco)proteins studied here, this effect may be augmented due to a salt gradient in the water-ice interface, which would further favor $\mathrm{AF}(\mathrm{G}) \mathrm{P}$ adsorption onto the ice crystals. Alternatively, specific ion-protein interactions could stabilize structural elements critical to the binding of $A F(G) P s$ to their respective ice crystal planes.

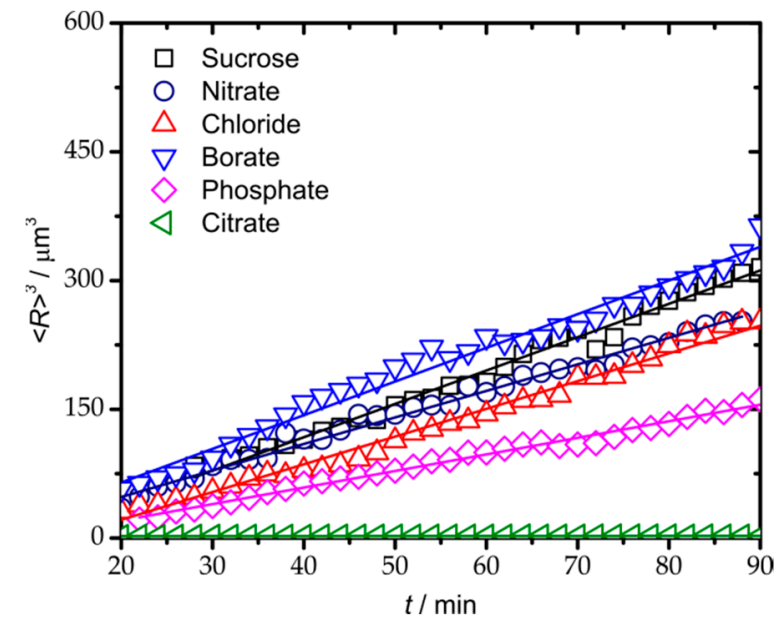

(a)

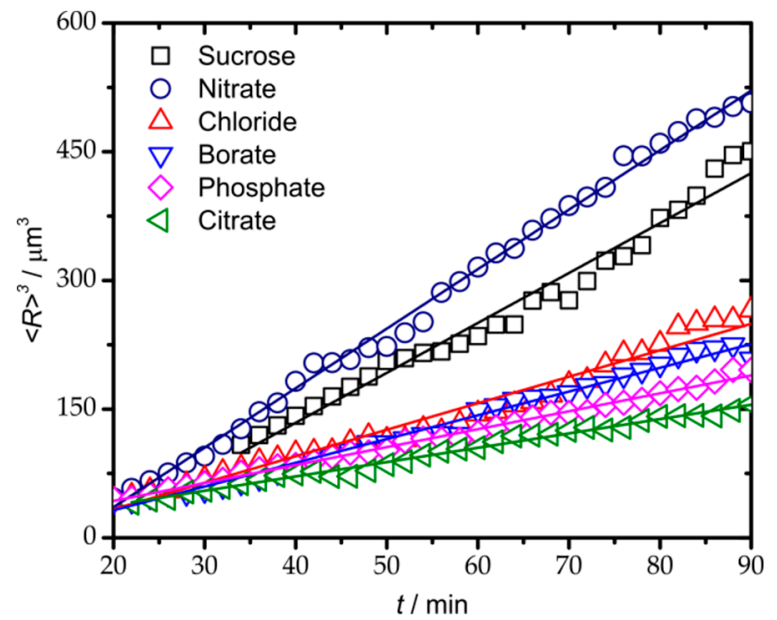

(b)

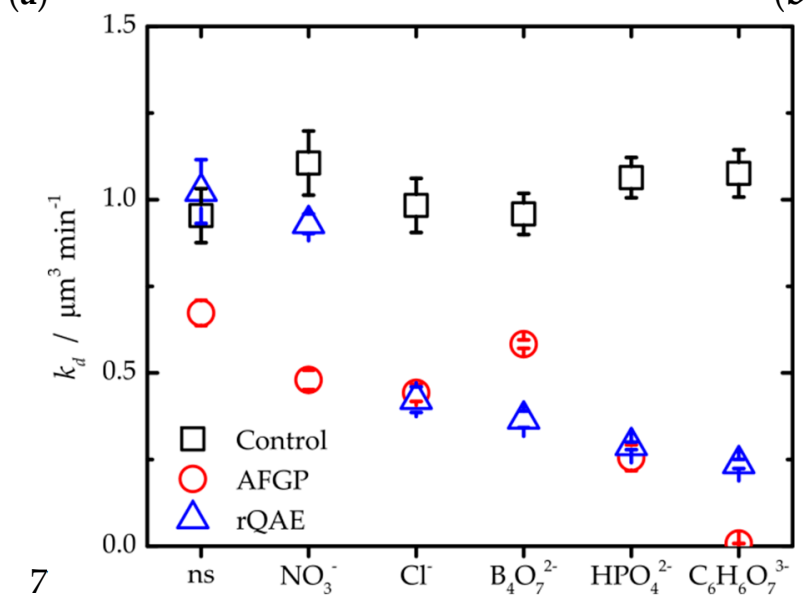

(c)

Figure 3. Ice growth rates $\left(k_{\mathrm{d}}\right)$ after annealing at $-7^{\circ} \mathrm{C}$ for $90 \mathrm{~min}$. (a) Samples containing $5 \mathrm{nM}$ AFGP $1-5$ in $30 \mathrm{wt} \%$ sucrose (black) without added salts, and with (navy blue) sodium nitrate, (red) sodium chloride, (blue) sodium borate, (magenta) sodium phosphate and (olive) sodium citrate. (b) Samples containing $500 \mathrm{nM}$ QAE in $30 \mathrm{wt} \%$ sucrose (black), sodium nitrate (navy blue), sodium chloride (red), sodium borate (blue), sodium phosphate (magenta) and sodium citrate (olive). (c) Ice growth rates for the salted reference solutions at a zero ice volume fraction regime for the reference solutions without proteins (black square), samples with $5 \mathrm{nM} \mathrm{AFGP}_{1-5}$ (red circle) and $500 \mathrm{nM} \mathrm{rQAE}$ (blue triangle).

Importantly, our findings also reveal a new strategy to boost the performance of AFGPs as cryoprotectants. In all cases except for $\mathrm{AFGP}_{1-5}$ in the presence of sodium borate, sodium salts boosted both IRI and TH in accordance with the Hofmeister series for anions. By contrast, sodium borate raised the IRI activity of $\mathrm{AFGP}_{1-5}$, while it simultaneously diminished its thermal hysteresis $(\mathrm{TH})$ activity [23]. This is exciting, as AFGPs are the most potent IRI active compounds known to date, but their utility in cryopreservation has remained limited. This is because their presence not only inhibits recrystallization, but also induces the formation of ice crystals with sharp edges, which are thought to cause cellular injury through, for example, membrane rupture. 


\section{Conclusions}

In conclusion, we have quantified the impact of sodium salts at a fixed ionic strength of $100 \mathrm{mM}$ on the ice recrystallization inhibition activity of two types of antifreeze (glyco)proteins. We found that all salts enhanced the IRI activity of rQAE and $\mathrm{AFGP}_{1-5}$ in accordance with the Hofmeister series for anions, with one exception, as previously reported by others for the TH activity of the insect antifreeze protein RiAFP and AFGP $1-5[17,26]$. Sodium nitrate had the weakest effect and sodium citrate the strongest. Surprisingly, sodium borate retained IRI activity of $\mathrm{AFGP}_{1-5}$ despite its reaction with the hydroxyl functionalities of $\mathrm{AFGP}_{1-5}$, which is known to diminish $\mathrm{TH}$ activity. The presence of salts clearly affected the performance of $\mathrm{AF}(\mathrm{G}) \mathrm{Ps}$, which may find use as additives in cryopreservation media to inhibit ice recrystallization and thereby alleviate cryoinjury. Our findings contribute to an improved understanding of the physical mechanisms that underpin the differential impact of excipients, specifically salts, on the performance of cryopreservation formulations.

Supplementary Materials: The following material is available online at http://www.mdpi.com/2218-273X/9/8/ 347/s1, Figure S1: Data acquisition and ice crystal analysis. Figure S2: Determination of ice growth rates from samples. Figure S3: sSart and end-point microphotographs. Figure S4: Log-normal ice crystal radii distributions of $\mathrm{AFGP}_{1-5}$. Figure S5: Log-nominal ice crystal radii distributions of rQAE. Table S1: Statistical analysis of normality. Table S2: Mann-Whitney-Wilcoxon tests.

Author Contributions: I.K.V conceived the project, I.K.V and R.S.V designed the experiments. R.S.V performed the experiments. R.S.V. and I.K.V. analyzed the data. I.K.V and R.S.V wrote the manuscript.

Funding: This work is financially supported by the European Union (ERC-2014-StG Contract No. 635928), and the Dutch Ministry of Education, Culture and Science (Gravity Program 024.001.035).

Acknowledgments: The authors acknowledge Konrad Meister and Arthur DeVries for providing AFGP ${ }_{1-5}$.

Conflicts of Interest: The authors declare no conflict of interest.

\section{References}

1. Mazur, P. Freezing of living cells: Mechanisms and implications. Am. J. Physiol. 1984, 247, C125-142. [CrossRef] [PubMed]

2. Scott, K.L.; Lecak, J.; Acker, J.P. Biopreservation of Red Blood Cells: Past, Present, and Future. Transfus. Med. Rev. 2005, 19, 127-142. [CrossRef] [PubMed]

3. Elliott, G.D.; Wang, S.; Fuller, B.J. Cryoprotectants: A review of the actions and applications of cryoprotective solutes that modulate cell recovery from ultra-low temperatures. Cryobiology 2017, 76, 74-91. [CrossRef] [PubMed]

4. DeVries, A.L. Glycoproteins as biological antifreeze agents in antarctic fishes. Science 1971, 172, $1152-1155$. [CrossRef]

5. Olijve, L.L.; Meister, K.; DeVries, A.L.; Duman, J.G.; Guo, S.; Bakker, H.J.; Voets, I.K. Blocking rapid ice crystal growth through nonbasal plane adsorption of antifreeze proteins. Proc. Natl. Acad. Sci. USA 2016, 113, 3740-3745. [CrossRef] [PubMed]

6. Kim, H.J.; Lee, J.H.; Hur, Y.B.; Lee, C.W.; Park, S.H.; Koo, B.W. Marine Antifreeze Proteins: Structure, Function, and Application to Cryopreservation as a Potential Cryoprotectant. Mar. Drugs 2017, 15, 27. [CrossRef]

7. Carpenter, J.F.; Hansen, T.N. Antifreeze protein modulates cell survival during cryopreservation: Mediation through influence on ice crystal growth. Proc. Natl. Acad. Sci. USA 1992, 89, 8953-8957. [CrossRef]

8. Lee, J.; Kim, S.K.; Youm, H.W.; Kim, H.J.; Lee, J.R.; Suh, C.S.; Kim, S.H. Effects of three different types of antifreeze proteins on mouse ovarian tissue cryopreservation and transplantation. PLOS ONE 2015, 10, e0126252. [CrossRef]

9. Wang, J.H. A comprehensive evaluation of the effects and mechanisms of antifreeze proteins during low-temperature preservation. Cryobiology 2000, 41, 1-9. [CrossRef]

10. Wang, T.; Zhu, Q.; Yang, X.; Layne, J.R., Jr.; Devries, A.L. Antifreeze glycoproteins from antarctic notothenioid fishes fail to protect the rat cardiac explant during hypothermic and freezing preservation. Cryobiology 1994, 31, 185-192. [CrossRef]

11. Kunz, W.; Henle, J.; Ninham, B.W. 'Zur Lehre von der Wirkung der Salze' (about the science of the effect of salts): Franz Hofmeister's historical papers. Curr. Opin. Colloid Interface Sci. 2004, 9, 19-37. [CrossRef] 
12. Salis, A.; Ninham, B.W. Models and mechanisms of Hofmeister effects in electrolyte solutions, and colloid and protein systems revisited. Chem. Soc. Rev. 2014, 43, 7358-7377. [CrossRef] [PubMed]

13. Yang, Z. Hofmeister effects: An explanation for the impact of ionic liquids on biocatalysis. J. Biotechnol. 2009, 144, 12-22. [CrossRef] [PubMed]

14. Zhang, Y.; Cremer, P.S. Interactions between macromolecules and ions: The Hofmeister series. Curr. Opin. Chem. Biol. 2006, 10, 658-663. [CrossRef] [PubMed]

15. Amornwittawat, N.; Wang, S.; Duman, J.G.; Wen, X. Polycarboxylates enhance beetle antifreeze protein activity. Proteins Proteom. 2008, 1784, 1942-1948. [CrossRef]

16. Duman, J.G. The inhibition of ice nucleators by insect antifreeze proteins is enhanced by glycerol and citrate. J. Comp. Physiol. B Biochem. Syst. Environ. Physiol. 2002, 172, 163-168. [CrossRef]

17. Kristiansen, E.; Pedersen, S.A.; Zachariassen, K.E. Salt-induced enhancement of antifreeze protein activity: A salting-out effect. Cryobiology 2008, 57, 122-129. [CrossRef] [PubMed]

18. Wang, S.; Amornwittawat, N.; Banatlao, J.; Chung, M.; Kao, Y.; Wen, X. Hofmeister Effects of Common Monovalent Salts on the Beetle Antifreeze Protein Activity. J. Phys. Chem. B 2009, 113, 13891-13894. [CrossRef]

19. Oude Vrielink, A.S.; Aloi, A.; Olijve, L.L.; Voets, I.K. Interaction of ice binding proteins with ice, water and ions. Biointerphases 2016, 11, 018906. [CrossRef]

20. Budke, C.; Dreyer, A.; Jaeger, J.; Gimpel, K.; Berkemeier, T.; Bonin, A.S.; Nagel, L.; Plattner, C.; DeVries, A.L.; Sewald, N.; et al. Quantitative Efficacy Classification of Ice Recrystallization Inhibition Agents. Crystal Growth Design 2014, 14, 4285-4294. [CrossRef]

21. Budke, C.; Heggemann, C.; Koch, M.; Sewald, N.; Koop, T. Ice recrystallization kinetics in the presence of synthetic antifreeze glycoprotein analogues using the framework of LSW theory. J. Phys. Chem. B 2009, 113, 2865-2873. [CrossRef] [PubMed]

22. Olijve, L.L.C.; Oude Vrielink, A.S.; Voets, I.K. A Simple and Quantitative Method to Evaluate Ice Recrystallization Kinetics Using the Circle Hough Transform Algorithm. Cryst. Growth Design 2016, 16, 4190-4195. [CrossRef]

23. Ahmed, A.I.; Yeh, Y.; Osuga, D.T.; Feeney, R.E. Antifreeze Glycoproteins from Antarctic Fish: Inactivation by borate. J. Biol. Chem. 1976, 251, 3033-3036. [PubMed]

24. Davis, H.B.; Mott, C.J.B. Interaction of boric acid and borates with carbohydrates and related substances. J. Chem. Soc. Faraday Trans. 1 Phys. Chem. Condens. Phases 1980, 76. [CrossRef]

25. Meister, K.; DeVries, A.L.; Bakker, H.J.; Drori, R. Antifreeze Glycoproteins Bind Irreversibly to Ice. J. Am. Chem. Soc. 2018, 140, 9365-9368. [CrossRef] [PubMed]

26. Meister, K.; Ebbinghaus, S.; Xu, Y.; Duman, J.G.; DeVries, A.; Gruebele, M.; Leitner, D.M.; Havenith, M. Long-range protein-water dynamics in hyperactive insect antifreeze proteins. Proc. Natl. Acad. Sci. USA 2013, 110, 1617-1622. [CrossRef] [PubMed]

(C) 2019 by the authors. Licensee MDPI, Basel, Switzerland. This article is an open access article distributed under the terms and conditions of the Creative Commons Attribution (CC BY) license (http://creativecommons.org/licenses/by/4.0/). 